\title{
Receptor role of the annexin A2 in the mesothelial endocytosis of crocidolite fibers
}

\author{
Kyoko Yamashita, Hirotaka Nagai and Shinya Toyokuni
}

\begin{abstract}
Asbestos-induced mesothelioma is a worldwide problem. Parietal mesothelial cells internalize asbestos fibers that traverse the entire lung parenchyma, an action that is linked to mesothelial carcinogenesis. Thus far, vitronectin purified from serum reportedly enhances the internalization of crocidolite by mesothelial cells via integrin $\alpha \mathrm{v} \beta 5$. To reveal another mechanism by which mesothelial cells endocytose (phagocytose) asbestos, we first evaluated the effects of serum on asbestos uptake, which proved to be nonessential. Thereafter, we undertook a study to identify proteins on the surface of mesothelial cells (MeT5A) that act as receptors for asbestos uptake based on the assumption that receptors bind to asbestos with physical affinity. To this end, we incubated the membrane fraction of MeT5A cells with crocidolite or chrysotile and evaluated the adsorbed proteins using sodium dodecyl sulfate polyacrylamide gel analysis. Next, we extensively identified the proteins using an in-solution or in-gel digestion coupled with mass spectrometry. Among the identified proteins, annexin A2 (ANXA2) and transferrin receptor protein 1 (TFRC) were distinguished because of their high score and presence at the cell surface. Crocidolite uptake by MeT5A cells was significantly decreased by shRNA (short hairpin RNA)-induced knockdown of ANXA2 and direct blockade of cell surface ANXA2 using anti-ANXA2 antibody. In addition, abundant ANXA2 protein was present on the cell membrane of mesothelial cells, particularly facing the somatic cavity. These findings demonstrate that ANXA2 has a role in the mesothelial phagocytosis of crocidolite and may serve as its receptor.

Laboratory Investigation (2015) 95, 749-764; doi:10.1038/labinvest.2015.28; published online 27 April 2015
\end{abstract}

Asbestos constitutes a group of minerals that occurs naturally in the environment as bundles of silicate fibers. Asbestos consists of the serpentine mineral chrysotile (white asbestos) and five amphibole minerals: crocidolite (blue asbestos), amosite (brown asbestos), tremolite, anthophyllite, and actinolite. Because asbestos is resistant to heat, acid, and friction, and possesses flexibility and economical merits, it had been widely used in industry worldwide over the past century. The peak world production of asbestos was estimated to be 5.09 million metric tons in 1975. However, concerns regarding the health risk from exposure to airborne asbestos caused a decline in asbestos use. ${ }^{1-3}$ Chrysotile, crocidolite, and amosite are the principal types of commercially used asbestos, with crocidolite considered the most hazardous. ${ }^{4}$ Occupational and environmental exposure to asbestos can result in several distinct disease entities, including asbestosis, pleural plaques, benign pleural effusion, lung cancer, and malignant mesothelioma (MM). Most of the cases of MM have been caused by asbestos inhalation, ${ }^{2,5,6}$ although some other fibers such as erionite, a specific zeolite mineral, could be the causative agent. ${ }^{7}$ In addition, genetic susceptibility and radiation were also suggested to be related to MM. ${ }^{8,9}$

The currently proposed three major hypotheses regarding the pathogenesis of asbestos-induced MM can be summarized as follows: ${ }^{10}$ (1) the 'oxidative stress theory' is based on epidemiological studies showing that asbestos fibers containing iron are more carcinogenic, ${ }^{11}$ and the fibers catalyze the generation of reactive species; ${ }^{12,13}$ (2) the 'chromosome tangling theory' postulates that asbestos fibers damage chromosomes when mesothelial cells divide; ${ }^{14,15}$ (3) the 'theory of adsorption of specific proteins as well as carcinogenic molecules' states that proteins and chemicals, such as components of cigarette smoke, are attached to the asbestos surface in vivo. ${ }^{15}$ Notably, these hypotheses are based on asbestos being able to enter mesothelial cells, and these complexes could be involved in the pathogenesis. ${ }^{16}$ In addition, chronic inflammation is suggested to be the hallmark of asbestos deposition in tissue, although it may contribute to 
asbestos-related carcinogenesis by the mechanisms mainly related to hypothesis $1 .{ }^{17,18}$ Macrophages that have engulfed asbestos may be frustrated owing to indigestion and release reactive species ${ }^{19}$ and numerous cytokines, including TNF- $\alpha$ and interleukin (IL)-1 $\beta$, both of which have been convincingly linked to the pathogenesis of asbestos-induced $M M{ }^{20}$ Necrotic mesothelial cells caused by asbestos release HMGB1, which can induce the secretion of TNF- $\alpha$ as well as the activation of the Nalp3 inflammasome and subsequent IL- $1 \beta$ secretion. ${ }^{20}$

Asbestos fibers are known to enter cells by endocytosis or phagocytosis and are covered by vesicular membrane structures. $^{21,22}$ We showed that the mesothelial endocytosis of crocidolite was accompanied by F-actin and Rab5a assembly. ${ }^{23}$ Reportedly, fiber internalization increased once the fiber was coated with vitronectin, and integrin $\alpha \mathrm{v} \beta 5$ was suggested to be a receptor for vitronectin-coated crocidolite $^{24,25}$ and chrysotile. ${ }^{26}$ However, even in those studies, a significant amount of asbestos fibers entered the cells in the absence of serum. Thus, other molecular mechanisms for endocytosis that are distinct from the one that exploit vitronectin and its receptor should exist.

Here, we examined the effects of serum on crocidolite and chrysotile endocytosis by mesothelial cells, and found that asbestos uptake was not reduced under serum-free conditions, contrary to a previous report. ${ }^{25}$ The asbestos surface is well known to adsorb proteins. ${ }^{27-29}$ Therefore, we hypothesized that asbestos fibers without a protein coating may bind to the receptor proteins on the mesothelial cell surface. To identify systematically the proteins involved in the mesothelial endocytosis of asbestos fibers, particularly candidate receptor proteins, we used an LTQ Orbitrap XL mass spectrometry system (Thermo Fisher Scientific, Waltham, MA, USA) combined with a Paradigm MS4 HPLC system (Michrom BioResources, Auburn, CA, USA), and evaluated the candidate proteins using shRNA (short hairpin RNA)-induced knockdown.

\section{MATERIALS AND METHODS Materials}

Chrysotile A, crocidolite, and amosite were obtained from the Union for International Cancer Control (UICC, Geneva, Switzerland) and suspended using vigorous sonication in normal saline to a concentration of $5 \mathrm{mg} / \mathrm{ml}$. To coat asbestos fibers with serum, crocidolite was incubated overnight with fetal bovine serum (FBS) (FBS Gold; PAA Laboratories, Cölbe, Germany) at a concentration of $1 \mathrm{mg} / \mathrm{ml}$. Next, the fibers were washed three times with normal saline and resuspended in normal saline at a final concentration of $5 \mathrm{mg} / \mathrm{ml}$. Thereafter, the coated fibers were sonicated for $1 \mathrm{~h}$ and used for experiments on the same day. Finally, all of the fiber suspensions were repeatedly passed through 23 -gauge needles.

\section{Reagents and Antibodies}

The following reagents and antibodies were used: Alexa Fluor 594 Phalloidin (Life Technologies, Carlsbad, CA, USA),
Hoechst 33342 (Dojindo, Kumamoto, Japan), Alexa Fluor 488 goat anti-rabbit secondary antibody (Life Technologies), and horseradish peroxidase-conjugated goat anti-rabbit secondary antibody (Dako, Glostrup, Denmark). The primary antibodies used were as follows: rabbit polyclonal antibody for ANXA2 (ab41803; Abcam, Cambridge, UK), rabbit polyclonal antibody for ANXA2 (sc-9061; Santa Cruz Biotechnology, Dallas, TX, USA), rabbit polyclonal antibody for TFRC (ab84036; Abcam), and mouse monoclonal antibody for $\beta$-actin (AC-15; Sigma Aldrich, St Louis, MO, USA). Normal rabbit IgG (Cell Signaling Technology, Danvers, MA, USA) was used as a control for antibody blocking.

\section{Cell Culture}

The human mesothelial cell line MeT5A was obtained from the American Type Culture Collection (ATCC, Manassas, VA, USA). MeT5A cells were maintained in Medium 199 containing $0.685 \mathrm{mM}$ L-glutamine, $2.2 \mathrm{~g} / \mathrm{l}$ sodium bicarbonate, $10 \mathrm{ng} / \mathrm{ml}$ epidermal growth factor, $400 \mathrm{nM}$ hydrocortisone, $870 \mathrm{nM}$ human recombinant insulin, $25 \mathrm{mM}$ HEPES, $2.8 \mathrm{ml} / \mathrm{l}$ trace elements B liquid from Mediatech (Manassas, VA, USA), and $10 \% \mathrm{FBS}$ in $5 \% \mathrm{CO}_{2}$ in air at $37^{\circ} \mathrm{C}$. In the experiments testing the endocytosis of asbestos by MeT5A cells, we also used serum-free medium and medium with $55 \%$ serum in the presence of the same ingredients as described above. We plated the cells at $2 \times 10^{4}$ cells per $\mathrm{cm}^{2}$ in 6- $\mathrm{cm}$ dishes $24 \mathrm{~h}$ before incubation with asbestos.

\section{Incubation of MeT5A Cells With Asbestos Fibers}

Different loading dosages $\left(1,2,3,5,10\right.$, and $\left.20 \mu \mathrm{g} / \mathrm{cm}^{2}\right)$ of asbestos and incubation times ( 2 and $24 \mathrm{~h}$ ) were applied in each experiment, with $4 \mathrm{ml}$ of media per dish. After incubation with fibers, the cells were washed three times with phosphate-buffered saline (PBS), trypsinized, and then resuspended in PBS. For flow cytometry, the cells were placed on ice until analysis, and we prepared a control sample for each analysis. The cells for the control sample were plated at $2 \times 10^{4}$ cells per $\mathrm{cm}^{2}$ one day before analysis and were subjected to the same conditions as those for the tests.

When testing the effects of serum on asbestos endocytosis and speed of asbestos to sink, we separated the samples into four groups based on the medium that was used for the incubation with asbestos and coating of asbestos fibers: (A) serum-free medium and uncoated asbestos; (B) medium with $10 \%$ FBS and uncoated asbestos, (C) serum-free medium and asbestos coated with FBS; and (D) medium with 10\% FBS and asbestos coated with FBS. OD600 was measured using GeneQuant 1300 (GE Healthcare, Wauwatosa, WI, USA) with a correction factor of 2.0.

In the experiments with direct blocking of ANXA2, we added anti-ANXA2 or normal rabbit IgG into the media to the final concentration of $10 \mu \mathrm{g} / \mathrm{ml}$ and incubated for $30 \mathrm{~min}$. Thereafter, the cells were washed with PBS, and $4 \mathrm{ml}$ of media were added. Next, crocidolite fibers $\left(2 \mu \mathrm{g} / \mathrm{cm}^{2}\right)$ were loaded and incubated for $2 \mathrm{~h}$. 


\section{Flow Cytometry}

We used flow cytometric analysis to quantify asbestos endocytosis, as described previously. ${ }^{30}$ Briefly, a BD FACSCalibur Flow Cytometer (BD Biosciences, San Jose, CA, USA) equipped with a 15-mW air-cooled argon ion laser excitation light source $(488 \mathrm{~nm})$ was used. Data acquisition and analysis were performed using Cell-Quest software (BD Biosciences). The data acquisition was stopped when 10000 events were counted, and the mean of the side scatter (SSC) values was calculated and represented as the 'mean SSC ratio (treated/ control), which was proved to be directly proportional to the amount of crocidolite fiber uptake including some membrane-associated fibers within a range of the forward scatter $>200$.

\section{Cell-Block Technique}

This technique is another method for quantifying crocidolite endocytosis that proved to be useful. ${ }^{30}$ To prepare a cell-block sample, we centrifuged the cells that had been resuspended in the medium at 800 r.p.m. $(120 \mathrm{~g})$ for $5 \mathrm{~min}$ and replaced the supernatant liquid with $10 \%$ neutral-buffered formalin (NBF). Next, the cells were embedded in paraffin to be handled as a routine tissue block and sectioned at a thickness of $4 \mu \mathrm{m}$. The cell-block sections were stained with hematoxylin-eosin (HE) or Kernechtrot. The latter was used for the counting of cells that engulfed the fibers.

\section{Collection and Analysis of Asbestos-Interacting Membrane Fraction Proteins}

Proteins in the membrane fraction of MeT5A cells were extracted and collected using the ProteoJET Membrane Protein Extraction Kit (Fermentas, Burlington, ON, Canada), according to the manufacturer's instructions. Protein concentrations were determined using a Protein Assay Bicinchoninate Kit (Nacalai Tesque, Kyoto, Japan).

To collect proteins adsorbed on asbestos fibers, we used an assay that was modified from previous experiments. ${ }^{15,29,31}$ For adsorption, asbestos fibers $(250 \mu \mathrm{g} / \mathrm{ml})$ were incubated with membrane fraction proteins $(1,2,5,10,20,50,100,150$, and $200 \mu \mathrm{g} / \mathrm{ml}$ ) in PBS in a total volume of $1 \mathrm{ml}$ at $37^{\circ} \mathrm{C}$ while being shaken at 200 r.p.m. for $30 \mathrm{~min}$. The mixture was then centrifuged $(20000 \mathrm{~g})$ at $4{ }^{\circ} \mathrm{C}$ for $5 \mathrm{~min}$, the supernatant was discarded, and the pellet was washed three times with PBS. After centrifugation, the supernatant was carefully discarded, and $30 \mu \mathrm{l}$ of sodium dodecyl sulfate-polyacrylamide gel analysis (SDS-PAGE) sample buffer $(62.5 \mathrm{mM}$ Tris- $\mathrm{HCl}$ buffer (pH 6.8), 2\% SDS, 7.5\% glycerol, 5\% 2-mercaptoethanol, $0.02 \%$ bromophenol blue) was directly added to the pellet and heated at $98^{\circ} \mathrm{C}$ for $5 \mathrm{~min}$. Thereafter, the sample was centrifuged $(20000 \mathrm{~g})$ at $4{ }^{\circ} \mathrm{C}$ for $2 \mathrm{~min}$, and $20 \mu \mathrm{l}$ of the supernatant was analyzed using SDS-PAGE. We stained the gels using a PlusOne Silver Staining Kit, Protein (GE Healthcare) following the manufacturer's protocol, except that we avoided using glutaraldehyde to minimize unnecessary protein modifications.

\section{Sample Preparation for Mass Spectrometry}

For the in-solution digestion method, we incubated fibers $(250 \mu \mathrm{g} / \mathrm{ml})$ with $200 \mu \mathrm{g} / \mathrm{ml}$ of membrane fraction proteins in PBS in a total volume of $1 \mathrm{ml}$ at $37^{\circ} \mathrm{C}$ while shaking at 200 r.p.m. for $30 \mathrm{~min}$. The fibers were pelleted and washed three times with PBS, and then the proteins that were bound to the fibers were eluted by heating for $5 \mathrm{~min}$ at $98^{\circ} \mathrm{C}$ in $40 \mu \mathrm{l}$ of $1 \times$ sample buffer $(62.5 \mathrm{mM}$ Tris-HCl buffer ( $\mathrm{pH} 6.8)$, 2\% SDS, 5\% 2-mercaptoethanol). After centrifugation, the supernatant $(25 \mu \mathrm{l})$ was passed through Pierce Detergent Removal Spin Columns (Thermo Fisher Scientific) and digested with trypsin for $16 \mathrm{~h}$ at $37^{\circ} \mathrm{C}$. Next, centrifugation was performed, and the middle layer was collected as the sample for mass spectrometry.

For the in-gel digestion method, fibers $(250 \mu \mathrm{g} / \mathrm{ml})$ were incubated with $200 \mu \mathrm{g} / \mathrm{ml}$ of membrane fraction proteins in a total volume of $1 \mathrm{ml}$ of PBS at $37^{\circ} \mathrm{C}$ while shaking at 200 r.p.m. for $30 \mathrm{~min}$. After SDS-PAGE and silver staining as described above, well-stained bands were randomly selected, excised, and prepared as samples for mass spectrometry, using the In-Gel Tryptic Digestion Kit (Thermo Fisher Scientific) according to the manufacturer's instructions.

\section{Mass Spectrometry}

Nanoelectrospray tandem mass analysis was performed using an LTQ Orbitrap XL mass spectrometry system combined with a Paradigm MS4 HPLC System (Michrom BioResources). A precursor ion scan was carried out using a 400-2000 mass to charge ratio $(\mathrm{m} / \mathrm{z})$ before MS/MS analysis. Multiple MS/MS spectra were submitted to the Mascot program (Matrix Science, Boston, MA, USA) for the MS/MS ion search. The NCBInr database (NCBInr 20111008) was searched for the peptides and proteins using taxonomy information of Homo sapiens as a filter, and the proteins and peptides were ranked using MudPIT scoring with the significance threshold set at 0.05 . The search parameters were as follows: the type of search, MS/MS ion search; enzyme, trypsin; variable modifications, carbamidomethyl (C) and oxidation (M); mass values, monoisotopic; protein mass, unrestricted; peptide mass tolerance, \pm 10 p.p.m.; fragment mass tolerance, $\pm 0.8 \mathrm{Da}$; max missed cleavages, 1; and instrument type, ESI-FTICR. When using Mascot, the protein score is derived from the ion scores, and the ion score for an MS/MS match is based on the calculated probability, $P$. The reported score is $-10 \log (P)$.

\section{Vector Design and Retroviral Transduction}

shRNA-expressing retrovirus vectors were constructed using the RNAi-Ready pSIREN-RetroQ Vector (Clontech, Mountain View, CA, USA) according to the supplier's instructions. The following sequences were selected as shRNA targets against two genes: ANXA2, which encodes ANXA2: $5^{\prime}$-TGTC AAAGCCTATACTAAC-3' (ANXA2-shRNA no. 1), 5' -ACTTT GATGCTGAGCGGGA-3' (ANXA2-shRNA no. 2) and 5'-CA 
ATGCACAGAGACAGGA-35' (ANXA2-shRNA no. 3), and TFRC, which encodes transferrin receptor protein 1 (TFRC): 5'-GCTACTTGGGCTATTGTAA-3' (TFRC-shRNA no. 1), 5'-GGTTATGTGGCGTATAGTA-3' (TFRC-shRNA no. 2) and 5'-AACTTCAAGGTTTCTGCCA-35' (TFRC-shRNA no. 3). A negative control shRNA-annealed oligonucleotide was also cloned into the RNAi-Ready pSIREN-RetroQ vector (control-shRNA). The correct insertion was confirmed using DNA sequencing with U6 primers. These constructs were co-transfected with pVSVG (Clontech) into the GP2-293 Packaging Cell Line (BD Biosciences) using Lipofectamine 2000 (Invitrogen) in OPTI-MEM medium (Invitrogen), and the culture supernatants were collected $48 \mathrm{~h}$ later. For infection, MeT5A cells were mixed with the supernatant containing virions in the presence of $8 \mu \mathrm{g} / \mathrm{ml}$ polybrene (Sigma Aldrich), and the transduced cells were subcultured and selected with $2 \mu \mathrm{g} / \mathrm{ml}$ puromycin. The expression of ANXA2 and TFRC was confirmed using western blotting.

\section{Western Blotting}

SDS-PAGE gels were processed for western blot analysis, transferred onto PVDF membranes, blocked with a reagent (N101; NOF Corporation; Tokyo, Japan), and then immunostained using the indicated primary antibodies and horseradish peroxidase-conjugated secondary antibodies. The probed proteins were visualized using the ECL Plus Western Blotting Detection System (GE Healthcare) as described previously. ${ }^{32}$ As an anti-ANXA2 antibody, ab41803 was used.

\section{Immunohistochemistry}

Sections that were cut at a $4-\mu \mathrm{m}$ thickness were dewaxed with xylene and ethanol, and subjected to high-temperature antigen retrieval in an immunosaver (Nisshin EM, Tokyo, Japan) for $40 \mathrm{~min}$. Next, the slides were dipped for $30 \mathrm{~min}$ in methanol containing $\mathrm{H}_{2} \mathrm{O}_{2}(0.3 \% \mathrm{v} / \mathrm{v})$ to quench endogenous peroxidase activity. After washing with PBS, the slides were incubated with primary antibodies and washed with PBS three times for $5 \mathrm{~min}$ each, and Histofine Simple Stain MAX-PO (Multi) (Nichirei, Tokyo, Japan) or Histofine Simple Stain Rat MAX-PO (Multi) (Nichirei) was applied to the slides. Anti-ANXA2 rabbit polyclonal antibody (ab41803) was used at a final concentration of $0.5 \mu \mathrm{g} / \mathrm{ml}$. Localization of antigen-antibody complexes was visualized as brown precipitates using DAB + Liquid (Dako, Kyoto, Japan) before nuclear counterstaining with hematoxylin.

\section{Immunofluorescence}

MeT5A cells were fixed in 10\% NBF for $20 \mathrm{~min}$. After three washes with $10 \mathrm{mM}$ PBS, $0.1 \%$ Triton $\mathrm{X}-100$ was added to the cells and incubated for $5 \mathrm{~min}$ for permeabilization. The cells were then washed three times with $10 \mathrm{mM}$ PBS and incubated with 3\% bovine serum albumin (BSA) in PBS for $30 \mathrm{~min}$ to block nonspecific binding of the antibodies. After washing with $\mathrm{PBS}, 1 \mu \mathrm{g} / \mathrm{ml}$ of an anti-ANXA2 rabbit polyclonal antibody (ab41803) was added to the cells and incubated for $30 \mathrm{~min}$ at room temperature. The cells were then washed three times with $0.1 \%$ BSA in PBS, incubated with $1 \mu \mathrm{g} / \mathrm{ml}$ Alexa 488-conjugated anti-rabbit IgG and $20 \mathrm{U} / \mathrm{ml}$ Alexa 594conjugated phalloidin for $30 \mathrm{~min}$, and then washed three times with $0.1 \%$ BSA in PBS. Nuclear counterstaining was performed using Hoechst 33342 solution ( $1 \mu \mathrm{g} / \mathrm{ml}$ in PBS) following the manufacturer's instructions. Finally, the samples were observed using a fluorescent microscope (BZ-9000; Keyence Corporation; Osaka, Japan).

\section{Animal Tissues}

Rat tissues obtained in our previous work were used. ${ }^{23}$ The animal experiment committee of Nagoya University Graduate School of Medicine approved this experiment.

\section{Statistical Analysis}

For the investigation of serum effects on crocidolite uptake, we used Tukey's multiple comparison test $(P<0.05)$ to compare the groups. We used paired Student's $t$-test $(P<0.05)$ for the influence of shRNA-mediated knockdown on crocidolite and chrysotile uptake, and direct blocking by the antibodies on crocidolite uptake.

\section{RESULTS}

Three Types of Asbestos Were Internalized by Mesothelial Cells

Chrysotile, crocidolite, and amosite fibers $\left(5 \mu \mathrm{g} / \mathrm{cm}^{2}\right)$ were incubated with MeT5A cells for $24 \mathrm{~h}$, and the uptake of the fibers was assessed using the cell-block technique and flow cytometry. Cell-block sections stained with HE revealed that all three fibers entered the MeT5A cells (Figure 1a). Crocidolite and amosite were composed of similar, dark, straight fibers, whereas chrysolite fibers were curled, white, and thinner than the other two. Thus, the chrysotile fibers were more difficult to identify by bright field observation. In the flow cytometric analysis, the SSC values were elevated after incubation with all three fibers. For crocidolite and amosite, the degree of elevation was nearly the same and higher than that of chrysotile (Figures $1 \mathrm{~b}$ and $\mathrm{c}$ ). Next, different doses of chrysotile, crocidolite, and amosite fibers $(1,2,3,5,10$, and $20 \mu \mathrm{g} / \mathrm{cm}^{2}$ ) were incubated with MeT5A cells for $2 \mathrm{~h}$. For all three types of fibers, the mean SSC ratio was directly proportional to the loading fiber dosage (Figure 1d), which suggested that it was also directly proportional to the amount of fibers uptake, and useful to quantify the uptake of these fibers including chrysotile and amosite.

\section{Serum Inhibited Crocidolite Endocytosis but did not Influence Chrysotile Endocytosis}

In the first experiment to test the effects of serum on crocidolite endocytosis, we separated the samples into the four groups as described in the Materials and Methods section (Groups A-D). The tests were performed nine times using $5 \mu \mathrm{g} / \mathrm{cm}^{2}$ of crocidolite with $2 \mathrm{~h}$ incubation time, and the mean SSC ratios (treated/control) of each group were 


\section{a}
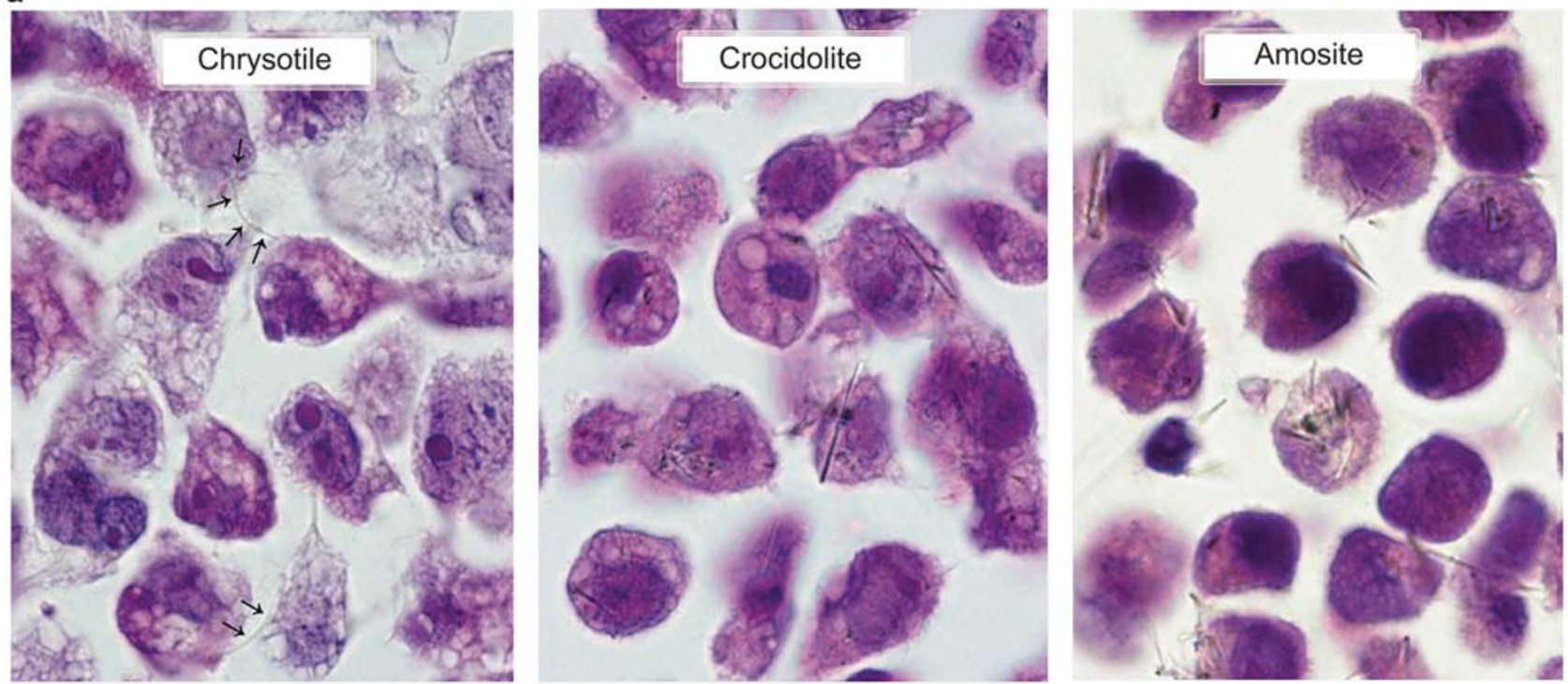

b
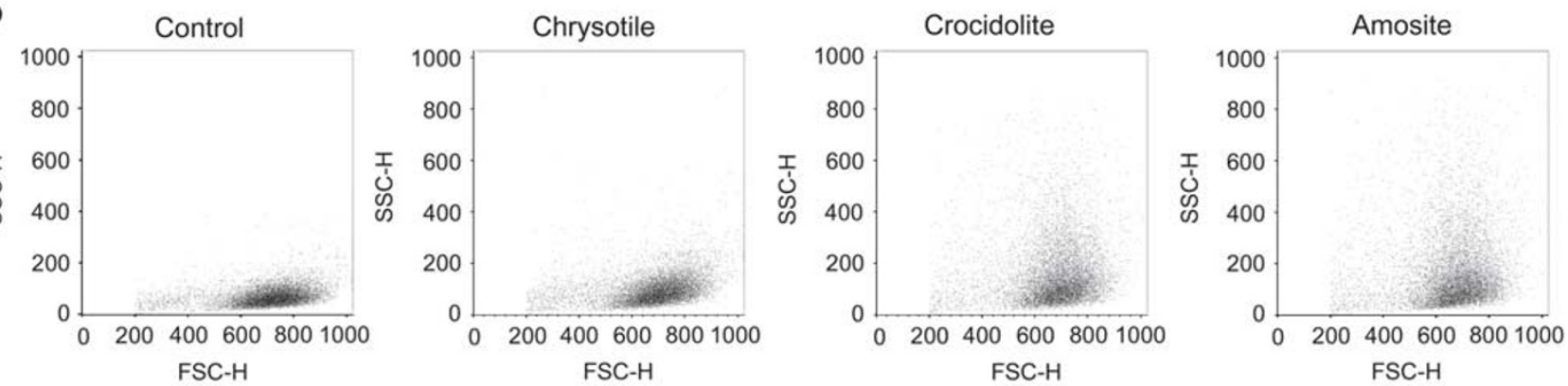

C
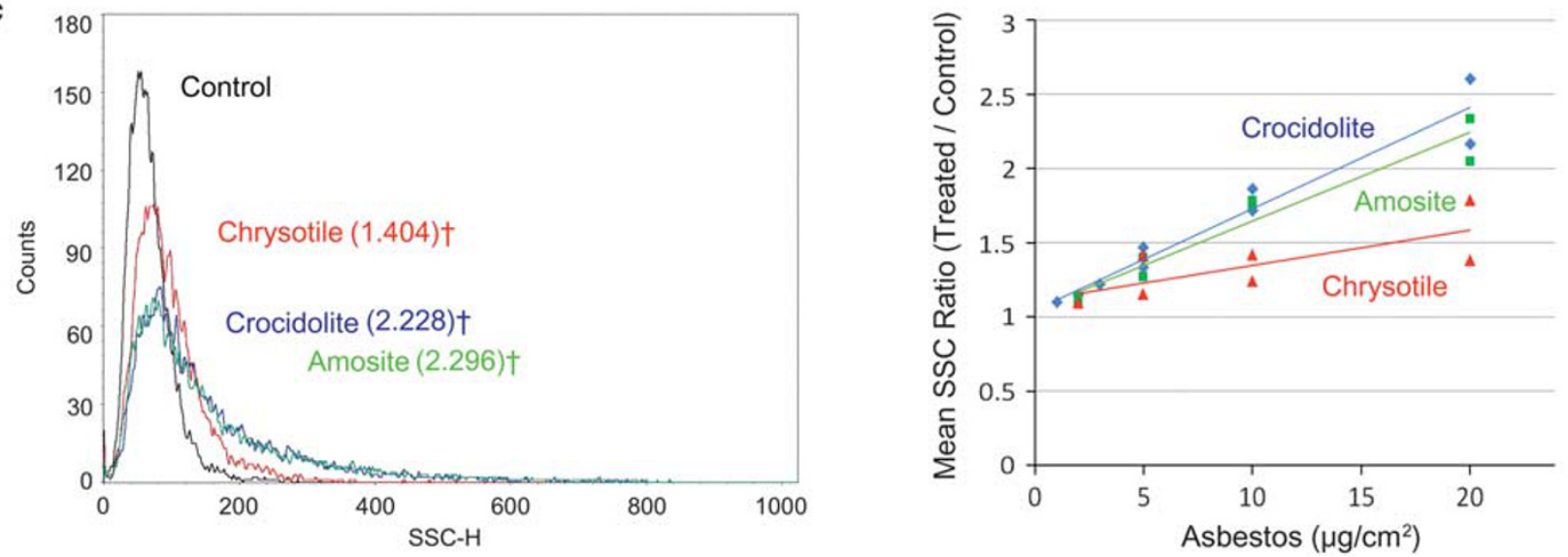

Figure 1 Evaluation of the uptake of three different asbestos fibers by mesothelial cells. (a) The cell-block sections of MeT5A cells after the uptake of asbestos. The sections were stained with hematoxylin and eosin, and images were taken at $\times 1000$ magnification (oil-immersion). White, curly fibers of chrysotile (arrows) and dark, straight fibers of crocidolite and amosite entered MeT5A cells. (b-d) The flow cytometric analysis of MeT5A cells after the uptake of asbestos. The cytograms (b) and histogram (c) indicated that the degrees of side scatter (SSC) increase after the uptake of crocidolite and amosite were nearly the same but greater than that after chrysotile uptake. The relationship with the increase in SSC was maintained regardless of the amount of asbestos (d). ${ }^{\dagger}$ Mean SSC ratio (treated/control).

compared (Figure 2a). The mean SSC ratio of Group A was significantly higher than those of the other three groups $(P<0.01)$. There was no significant difference between the other pairs of groups $(P>0.05)$, whereas Group B tended to show a higher mean SSC ratio than both Groups C and D. We also performed the same experiment using chrysotile fibers. After repeating the tests six times, no significant difference was found among the groups $(P>0.05)$ (Figure 2a). 

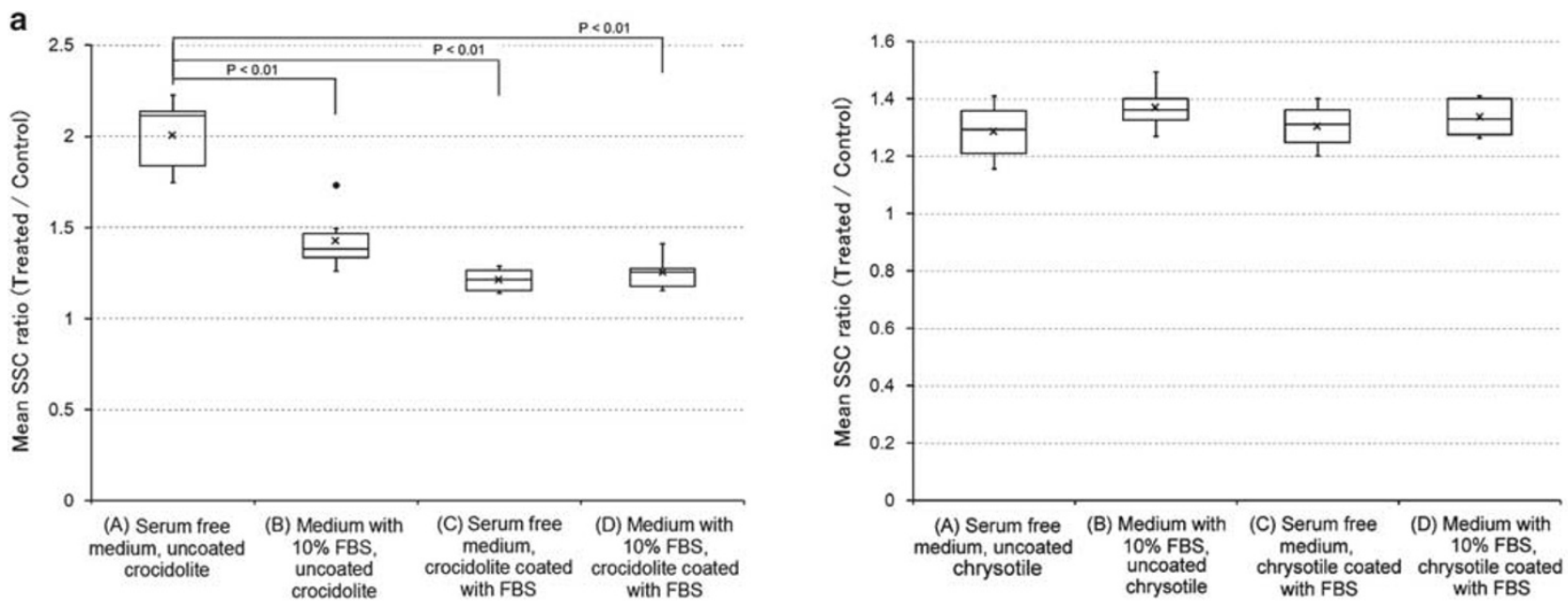

b
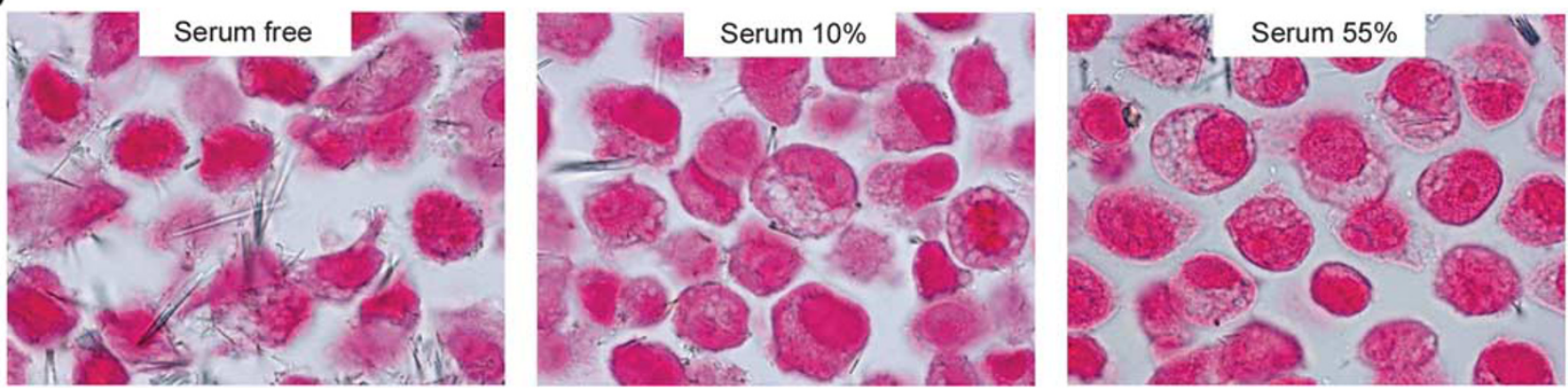

Figure 2 The effects of serum on crocidolite and chrysotile uptake by mesothelial cells. (a) Box-plot diagrams show the results of nine tests for crocidolite and six tests for chrysotile concerning the influence of serum in the media and serum coating of the fibers on the mean side scatter (SSC) ratio (fiber uptake). The cross sign within the central box indicates the mean value; outliers (which are shown as dots) are points that extend more than 1.5 times the interquartile range. Data were evaluated by Tukey's test. (b) The cell-block sections of MeT5A cells after the uptake of crocidolite fibers. The sections were stained with Kernechtrot stain, and images were taken at $\times 1000$ magnification (oil-immersion).

In the second experiment, MeT5A cells were incubated in a medium of 0,10 , or $55 \%$ serum with $5 \mu \mathrm{g} / \mathrm{cm}^{2}$ of uncoated crocidolite fibers for $2 \mathrm{~h}$. This experiment was analyzed using flow cytometry and the cell-block technique (Table 1 and Figure 2b). Both techniques produced similar results: the quantity of crocidolite uptake was the largest in cells under the serum-free condition, and was the smallest in cells incubated with crocidolite in medium with 55\% FBS.

To investigate the effect of serum on the required time of added crocidolite fibers to reach the bottom of dish where MeT5A cells were attached, we separated the samples into the four groups described in the Materials and Methods section (Groups A-D) again. In each group, we added $300 \mu \mathrm{l}$ $(1500 \mu \mathrm{g})$ of crocidolite fibers to $1600 \mu \mathrm{l}$ of the medium in a $2-\mathrm{ml}$ microtube, mixed them by turning the tube upside down several times, and allowed it to stand under $5 \% \mathrm{CO}_{2}$ in air at $37^{\circ} \mathrm{C}$ for $2 \mathrm{~h}$. We found that only Group A had clear medium, with almost all of the crocidolite fibers reaching the bottom (Supplementary Figure 1a). There was no apparent difference among the other three groups. The OD600 of $1 \mathrm{ml}$ of supernatant fluid was measured in each group. The OD600 of Group A was less than one-tenth of that of the other groups (Supplementary Table 1). We also performed the same experiment using $300 \mu \mathrm{l}(1500 \mu \mathrm{g})$ of chrysotile fibers. We were not able to find consistent difference among the four groups, presumably because of technical difficulties in generating consistent data (Supplementary Figure 1b). In the experiment using chrysotile, we did not measure the OD600 because we could not obtain $1 \mathrm{ml}$ of homogeneous supernatant fluid from all of the groups.

After serum-free stress for $2 \mathrm{~h}$ without asbestos treatment, we found the number of cells tended to detach from the bottom slightly increased (Supplementary Figure 2a). No significant difference was observed in the overall cell size, although the cells appeared degenerated, and the number of apoptotic cells was slightly increased as far as we could find in the HE-stained specimens (Supplementary Figure 2b).

\section{Asbestos Fibers Adsorbed Various Proteins Depending on the Type of Fiber}

Three types of asbestos fibers $(250 \mu \mathrm{g} / \mathrm{ml})$ were incubated with $150 \mu \mathrm{g} / \mathrm{ml}$ of MeT5A membrane fraction proteins. 
Table 1 Influence of FBS on the crocidolite fiber uptake examined by two methods

\begin{tabular}{lcc}
\hline Serum in incubation medium (\%) & 0 & 10 \\
\hline Mean SSC ratio (treated/control) & 2.074 & 1.346 \\
Cells without crocidolite (\%) $^{\mathrm{a}}$ & 6.06 & 1.303 \\
Cells including $<5$ bundles of crocidolite fiber (\%) $^{\mathrm{a}}$ & 13.8 & 31.7 \\
Cells including 5 or more bundles of crocidolite fiber/crocidolite in clumps (\%) $^{\mathrm{a}}$ & 80.1 & 45.9 \\
Total counted cell numbers $^{\mathrm{a}}$ & 578 & 32.4 \\
\hline
\end{tabular}

Abbreviations: FBS, fetal bovine serum; SSC, side scatter.

MeT5A cells were grown to $70 \%$ confluence $\left(2 \times 10^{4}\right.$ cells per $\mathrm{cm}^{2}, 24 \mathrm{~h}$ before) and incubated with $5 \mu \mathrm{g} / \mathrm{cm}^{2} \mathrm{crocidolite}$ for $2 \mathrm{~h}$.

${ }^{\mathrm{a} C o u n t e d}$ by cell block.

Crocidolite and amosite showed nearly the same pattern of protein adsorption, whereas chrysotile showed a slightly different pattern (Figure 3a). Next, crocidolite and chrysotile fibers $(250 \mu \mathrm{g} / \mathrm{ml})$ were incubated with membrane fraction proteins at different concentrations. Most of the adsorbed proteins increased with the amount of membrane fraction protein used in the incubation, whereas some adsorbed proteins did not increase or even decreased most likely because of their relatively low affinity for crocidolite (Figure 3b).

\section{Asbestos-Interacting Membrane Proteins Were Identified Using Mass Spectrometry}

First, the membrane fraction proteins that were adsorbed to crocidolite fibers were prepared using in-gel digestion. After sample preparation and SDS-PAGE, followed by silver staining, 17 distinct protein bands (shown by arrows in Figure $3 \mathrm{~b}$ ) were excised from the gel and analyzed by mass spectrometry. Representative proteins which we picked out by the score, the location in cells and the supposed functions are shown in Table 2 (all of the identified proteins are shown in Supplementary Table 2).

Thereafter, the membrane fraction proteins that were adsorbed to crocidolite and chrysolite fibers were analyzed using an in-solution approach with mass spectrometric analysis. Among the proteins identified using mass spectrometry, those with a score $>100$ were classified into nine categories, depending on the intracellular localization with overlapping distribution (Supplementary Tables 3 and 4). The proteins belonging to the 'transmembrane protein of plasma membrane' and the 'protein at cell surface' categories are shown in Tables 3 and 4 . The proteins of these two categories were exposed to the extracellular environment and were expected to bind to asbestos fibers before endocytosis.

\section{Crocidolite Uptake was Suppressed by ANXA2 Knockdown but not by TFRC Knockdown}

As candidate proteins that adhere to crocidolite fibers initiate endocytosis, we selected ANXA2 and TFRC because ANXA2 obtained the highest score of the two categories shown in Table 3, and TFRC is a well-known receptor for receptor-mediated endocytosis. To knock down ANXA2 and TFRC, we constructed three shRNA-expressing retroviral vectors for each protein. Virus-mediated transfection with ANXA2-shRNA no. 1 and TFRC-shRNA no. 2 successfully reduced the protein levels of ANXA2 to one-fifth and TFRC to one-third of the total level, respectively (Figure 4a).

In the experiments to test the knockdown effects of these two genes using flow cytometry, crocidolite fibers $\left(2 \mu \mathrm{g} / \mathrm{cm}^{2}\right)$ were incubated with MeT5A cells transfected with each shRNA for $2 \mathrm{~h}$, and the experiments were performed five times for both genes. The mean SSC ratio (treated/control) of the ANXA2-shRNA no. 1-transfected MeT5A cells was significantly lower than that of the control-shRNA-transfected MeT5A cells $(P<0.05)$. By contrast, the TFRC-shRNA no. 2-transfected MeT5A cells did not show a significant difference in the mean SSC ratio $(P=0.219)$ (Figure $4 \mathrm{~b})$. To verify the knockdown effect of ANXA2, we also performed the analysis using the cell-block technique in one of the five tests and found that the amount of crocidolite uptake was smaller in the ANXA2-shRNA no. 1-transfected MeT5A cells than in the control-shRNA-transfected MeT5A cells (Table 5). Both of these results indicated that shRNA-induced ANXA2 knockdown of MeT5A cells results in a reduction of crocidolite uptake.

\section{Crocidolite Uptake Was Significantly Suppressed by Direct Blockade With ANXA2 Antibody}

Direct blockade of ANXA2 on the cell surface was performed using two different anti-ANXA2 antibodies, and analyzed by flow cytometry. After nine repeated tests, the mean SSC ratio (treated/control) of the MeT5A cells blocked by anti-ANXA2 antibody (ab41803) was significantly lower than that of the cells treated with control-IgG $(P<0.05)$ (Figure $4 \mathrm{c})$. However, we could not find significant difference or even obvious tendency using a different anti-ANXA2 antibody (sc-9061) $(P=0.440)$ (Supplementary Figure 3). 
a

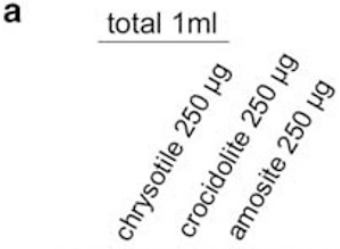

membrane protein $150 \mu \mathrm{g}$

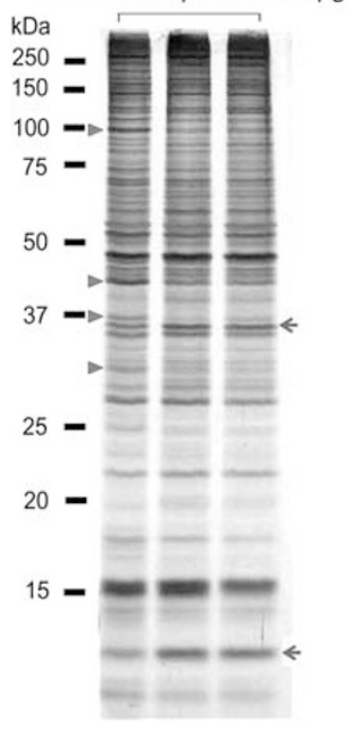

b
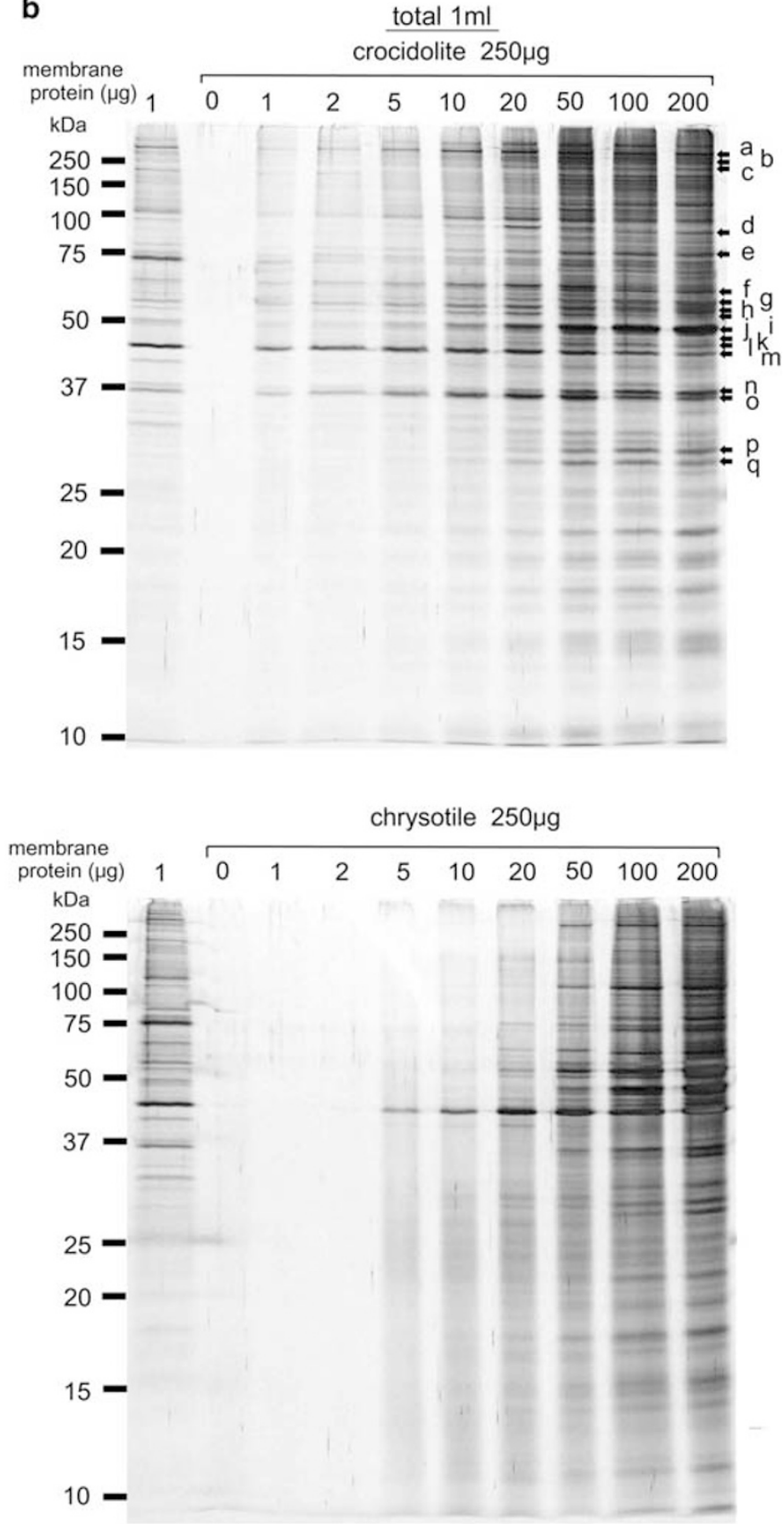

Figure 3 Analysis of membrane fraction proteins adsorbed by three different types of asbestos fibers. Adsorbed proteins were analyzed using sodium dodecyl sulfate-polyacrylamide gel analysis (SDS-PAGE), followed by silver staining. (a) Crocidolite, chrysotile, and amosite fibers ( $250 \mu \mathrm{g} / \mathrm{ml}$ ) were incubated with $150 \mu \mathrm{g} / \mathrm{ml}$ of MeT5A membrane fraction proteins. Crocidolite and amosite showed nearly the same pattern, adsorbing some proteins more strongly than chrysotile (arrows) and adsorbing other proteins more weakly (arrowheads). (b) Crocidolite and chrysotile fibers ( $250 \mu \mathrm{g} / \mathrm{ml})$ were incubated with MeT5A membrane fraction proteins $(0,1,2,5,10,20,50,100$, and $200 \mu \mathrm{g} / \mathrm{ml})$, respectively. Membrane fraction proteins $(1.0 \mu \mathrm{g})$ were analyzed simultaneously. For crocidolite, some bands of proteins were prepared using in-gel digestion to be analyzed using an LTQ Orbitrap XL mass spectrometry system (arrows); the identified proteins are shown in Table 2 and Supplementary Table 2. The color reproduction of this figure is available on the Laboratory Investigation journal online.

\section{Adsorption Capacity of Asbestos Analyzed by Western Blotting Was Compatible With the Results of Mass Spectrometry}

Using western blotting analysis, we also determined the adsorption capacity of asbestos to ANXA2 and TFRC.
We observed that all three types of asbestos fibers adsorbed these two proteins, and chrysotile adsorbed a larger amount of TFRC than crocidolite and amosite, whereas chrysotile adsorbed a smaller amount of ANXA2 than the other two (Figure 4d). These findings are consistent with the results of 
Plasma membrane

a

b

d

e

f

g

h

k

n

$\mathrm{p}$

q
Ras GTPase-activating-like protein IQGAP1 (1139)

Eukaryotic translation initiation factor 3 subunit A (316)

Thrombospondin-1 (116)

Filamin A (1145)

Neuroblast differentiation-associated protein AHNAK isoform 1 (249)

Myosin-9 (483)

ATP-dependent RNA helicase DDX1 (243)

6-Phosphofructokinase type C isoform 1 (229)

Mannosyl-oligosaccharide glucosidase isoform (217)

Keratin 1 (832)

Keratin 1 (431)

Pyruvate kinase (307)

Vimentin (739)

ATP synthase subunit $\alpha$, mitochondrial precursor (265)

Aspartyl-tRNA synthetase, cytoplasmic (256)

Eukaryotic translation initiation factor 2 subunit 3 (268)

Elongation factor $1-\alpha 1$ (1118)

Elongation factor $1-\alpha 2$ (693)

Trifunctional enzyme subunit $\beta$, mitochondrial precursor (374)

Cytochrome b-c1 complex subunit 2, mitochondrial precursor (392)

Elongation factor Tu (382)

Actin, cytoplasmic $1(540)$

Isocitrate dehydrogenase [NADP], mitochondrial precursor (380)

Glyceraldehyde-3-phosphate dehydrogenase (242)

eukaryotic translation initiation factor 2 subunit 1 (218)

Annexin A2 isoform 2 (413)

S3 ribosomal protein (787)

40 S ribosomal protein $\mathrm{S} 4, \mathrm{X}$ isoform $\mathrm{X}$ isoform (348)

() Indicates protein scores. Refer to Materials and Methods section for the details of protein scores. Bands are shown in Figure 3. 
Table 3 Adsorbed proteins to crocidolite identified in solution digestion (scores over 100)

\begin{tabular}{cccccll}
\hline Score & Matches & Sequences & emPAl & Mass & Gl number & Protein \\
\hline \multicolumn{7}{l}{ Transmembrane protein of plasma membrane } \\
318 & $21(14)$ & $17(12)$ & 0.47 & 112824 & Gi|21361181 & Sodium/potassium-transporting ATPase subunit $\alpha-1$ isoform a \\
200 & $17(12)$ & $13(10)$ & 0.53 & 85811 & Gi|62088088 & Transferrin receptor variant \{Transferrin receptor protein 1\} \\
175 & $15(12)$ & $12(10)$ & 0.87 & 57790 & Gi|306896 & Intercellular adhesion molecule-1 precursor \\
161 & $14(9)$ & $11(8)$ & 0.68 & 55780 & Gi|9295347 & GK001 (coiled-coil domain-containing protein 47) \\
143 & $4(4)$ & $2(2)$ & 0.83 & 11302 & Gi|4759300 & Vesicle-associated membrane protein 3
\end{tabular}

Protein at cell surface

$\begin{array}{lccllll}605 & 38(28) & 22(21) & 9.17 & 38580 & \text { Gi|4757756 } & \text { Annexin A2 isoform } 2 \\ 303 & 13(11) & 9(8) & 1.1 & 38690 & \text { Gi|4502101 } & \text { Annexin A1 } \\ 246 & 18(10) & 13(10) & 0.83 & 59714 & \text { Gi|4757810 } & \text { ATP synthase subunit } \alpha \text {, mitochondrial precursor } \\ 201 & 13(6) & 12(5) & 0.23 & 88890 & \text { Gi|32358 } & \text { hnRNP U protein } \\ 198 & 11(10) & 9(9) & 0.61 & 68005 & \text { Gi| } 5031815 & \text { Lysyl-tRNA synthetase isoform 2 } \\ 162 & 8(7) & 5(5) & 1.42 & 23971 & \text { Gi|20147713 } & \text { Ras family small GTP-binding protein RALA }\end{array}$

\{\} Indicates equal or highly similar protein.

mass spectrometry, where TFRC obtained the highest score among the transmembrane proteins of the plasma membrane adsorbed to chrysotile, while the score of ANXA2 adsorbed to chrysotile was only 72 .

\section{Chrysotile Uptake Was Mildly but not Significantly Suppressed by TFRC Knockdown and Was not Influenced by ANXA2 Knockdown}

To compare chrysotile with crocidolite, ANXA2 and TFRC knockdown analyses were also performed on chrysotile using flow cytometry following the same protocol, and the experiments were performed six times for each gene. The mean SSC ratio (treated/control) of the ANXA2-shRNA no. 1-transfected MeT5A cells was nearly the same as that of the control-shRNA-transfected MeT5A cells $(P=0.593)$. The TFRC-shRNA no. 2-transfected MeT5A cells tended to have a lower mean SSC ratio compared with the control-shRNAtransfected MeT5A cells, but this difference was not statistically significant $(P=0.267)$ (Figure $4 \mathrm{e})$.

\section{ANXA2 Was Abundant on the Plasma Membrane of Mesothelial Cells, Particularly on the Peritoneal Cavity Side}

We performed immunofluorescence (IF) and immunohistochemical analyses of MeT5A cells and the peritoneal mesothelia and peritoneal MM of rats using anti-ANXA2 antibody (Figures $5 \mathrm{a}-\mathrm{f}$ ). ANXA2 was expressed consistently on the plasma membranes of MeT5A cells (Figures $5 \mathrm{a}$ and $\mathrm{b}$ ), and its expression was observed on the surface of the normal peritoneum of rat (Figures $5 \mathrm{c}$ and $\mathrm{d}$ ) and on the plasma membrane of the epithelioid (Figure 5e) and sarcomatoid subtypes (Figure 5f) of rat MM cells. Regarding the MM cells of the epithelioid subtype, ANXA2 was expressed on the cell membrane at the apical side, facing the peritoneal cavity.

\section{DISCUSSION}

We studied the endocytosis of asbestos by mesothelial cells, focusing on its candidate receptors. In the crocidolite uptake, we showed the possibility of cell-surface ANXA2 as its receptor in addition to the non-essential role of serum. In the cell-block section of MeT5A cells that was incubated with asbestos, crocidolite and amosite appeared similar and were easy to identify. In the flow cytometric analysis, they also showed similar mean SSC ratios (treated/control) being loaded with the same dosage. By contrast, chrysotile appeared different, presenting a challenge regarding its identification in the cell-block section, and showing a lower mean SSC ratio (treated/control) than the other two asbestos in flow cytometry. However, the mean SSC ratios (treated/control) of chrysotile and amosite were directly proportional to the loaded amounts of fibers, as well as crocidolite. We previously showed that flow cytometry is useful for the quantitative assessment of crosidolite uptake by mesothelial cells based on the rationale that SSC is dependent on the presence of intracellular structures not excluding some membranous ones that change the refractive index of light. ${ }^{30}$ The results of the current study suggest that SSC would be useful for the quantitative assessment of asbestos uptake by mesothelial cells not only for crocidolite but also for chrysotile and amosite, although we cannot compare the different types of fibers because of their differences in shape and property. In flow cytometric analysis, we have to consider minimizing the 
Table 4 Adsorbed proteins to chrysotile identified in solution digestion (scores over 100)

\begin{tabular}{ccccccl}
\hline Score & Matches & Sequences & emPAl & Mass & Gl number & Protein \\
\multicolumn{7}{c}{ Transmembrane protein of plasma membrane } \\
519 & $35(22)$ & $25(15)$ & 0.98 & 84848 & Gi|37433 & Unnamed protein product \{Transferrin receptor protein 1\} \\
482 & $34(21)$ & $25(15)$ & 0.91 & 89654 & Gi|119574056 & Transferrin receptor (p90, CD71), isoform CRA_b \\
256 & $13(8)$ & $10(5)$ & 0.38 & 55780 & Gi| 9295347 & GK001 (coiled-coil domain-containing protein 47) \\
229 & $6(6)$ & $3(3)$ & 1.96 & 12641 & Gi|27806183 & Vesicle-associated membrane protein 2 \\
172 & $9(6)$ & $7(5)$ & 0.34 & 62023 & Gi|19263767 & Similar to cytoskeleton-associated protein 4, partial \{Cytoskeleton-associated protein 4\} \\
146 & $15(6)$ & $15(6)$ & 0.09 & 250342 & Gi|34148711 & Melanoma chondroitin sulfate proteoglycan \{Chondroitin sulfate proteoglycan 4\} \\
141 & $15(7)$ & $12(5)$ & 0.17 & 112824 & Gi|21361181 & Sodium/potassium-transporting ATPase subunit $\alpha$-1 isoform a \\
140 & $4(4)$ & $3(3)$ & 2.34 & 11303 & Gi|13543574 & Vesicle-associated membrane protein 3 (cellubrevin) \\
128 & $3(3)$ & $1(1)$ & 0.07 & 53563 & Gi|29801 & CD44E (epithelial form) \\
123 & $13(8)$ & $11(8)$ & 0.65 & 57790 & Gi|306896 & Intercellular adhesion molecule-1 precursor \\
115 & $5(4)$ & $5(4)$ & 0.28 & 57935 & Gi|177207 & 4F2 antigen heavy chain \\
107 & $15(7)$ & $12(5)$ & 0.28 & 88357 & Gi|19743813 & Integrin $\beta$-1 isoform 1A precursor \\
103 & $8(4)$ & $7(3)$ & 0.11 & 108185 & Gi|181944 & Protein-tyrosine kinase \{Ephrin type-A receptor 2\}
\end{tabular}

Protein at cell surface

$\begin{array}{lllllll}556 & 24(18) & 17(13) & 1.48 & 59714 & \text { Gi|} 4757810 & \text { ATP synthase subunit } \alpha \text {, mitochondrial precursor } \\ 408 & 21(14) & 16(13) & 1.14 & 61611 & \text { Gi|31847 } & \text { Glypican } \\ 237 & 13(7) & 12(6) & 0.28 & 88890 & \text { Gi|32358 } & \text { hnRNP U protein } \\ 165 & 14(10) & 11(10) & 0.32 & 129330 & \text { Gi|37138 } & \text { Unnamed protein product \{Thrombospondin-1\} } \\ 135 & 6(6) & 5(5) & 1.09 & 23971 & \text { Gi|20147713 } & \text { Ras family small GTP-binding protein RALA } \\ 132 & 9(7) & 7(7) & 1.86 & 23554 & \text { Gi|88191913 } & \text { Chain A, crystal structure of the thrombospondin-1 N-terminal domain } \\ & & & & & & \\ & & & & & & \end{array}$

\{\} Indicates equal or highly similar protein.

time lag among samples because SSC may slightly increase over time.

We observed the largest amount of crocidolite uptake in mesothelial cells under serum-free conditions; this result was in contrast to those of previous reports using pulmonary epithelial cells ${ }^{25,33}$ and macrophages. ${ }^{34,35}$ We believe that the difference in the speed at which crocidolite fibers sink had influenced the results, although the depth of the medium during incubation was only $<0.2 \mathrm{~cm}$ (6-cm dish with $4 \mathrm{ml}$ of medium). OD600 represents the clarity of medium, so the supernatant of serum-free Group A was proven to be much clearer than that of the other groups because most of the crocidolite fibers had reached the bottom within $2 \mathrm{~h}$ and were not included in the supernatant medium in Group A unlike the other three groups. We believe that the increase in viscosity of the medium by adding serum and the change in the size and shape of fibers as a result of aggregation by serum-coating mainly produced this phenomenon. Serum-coated fibers tended to aggregate with each other, so we attempted to minimize this aggregation through the immediate use of the fibers after a 1-h sonication on the same day that the coating process was completed. However, the influence of serum-coating may have persisted. The shape, size, and protein adsorbability of chrysotile fibers were different from those of crocidolite fibers, and we observed no consistent tendency in the speed at which chrysotile fibers sink among the four groups. We also observed no significant difference in the amount of chrysotile uptake among the four groups. Even considering the difference in the amounts of fibers that had reached the bottom of the dish, we could state that significant amounts of both crocidolite and chrysotile fibers entered the cells without serum, and serum was not essential for asbestos endocytosis. Until now, the only known pathway for the initiation of the endocytosis of asbestos was the association of serum-derived vitronectin with integrin $\alpha \mathrm{v} \beta 5$ on the mesothelial cell surface. ${ }^{24}$ Our results suggest that there may be endocytosis mechanisms that differ from those that use protein coating of asbestos, although we do not deny the importance of the mechanism using vitronectin coating in vivo. 
a

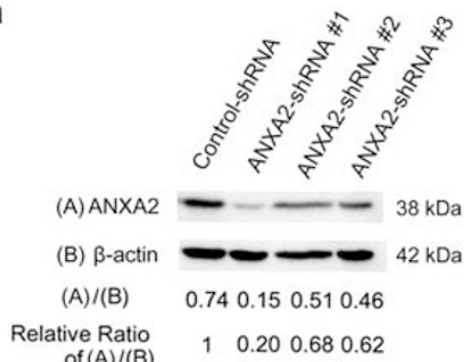

b [crocidolite $2 \mu \mathrm{g} / \mathrm{cm}^{2}$ ]

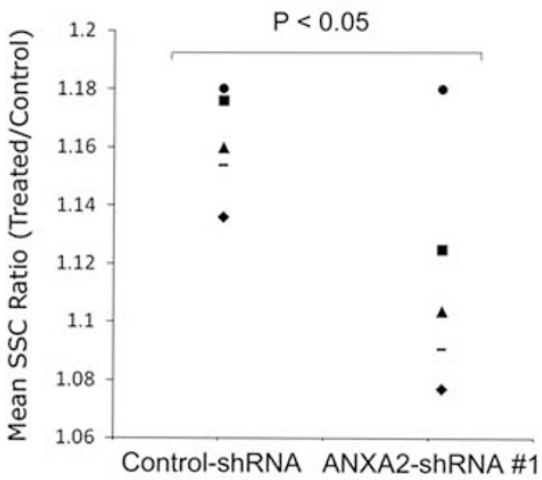

C [crocidolite $2 \mu \mathrm{g} / \mathrm{cm}^{2}$ ]

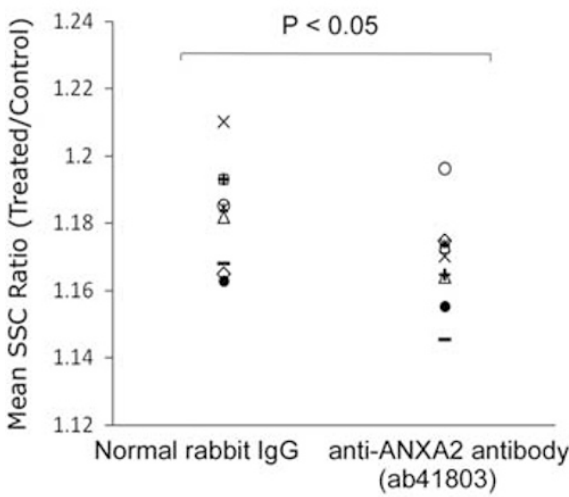

e [chrysotile $5 \mu \mathrm{g} / \mathrm{cm}^{2}$ ]

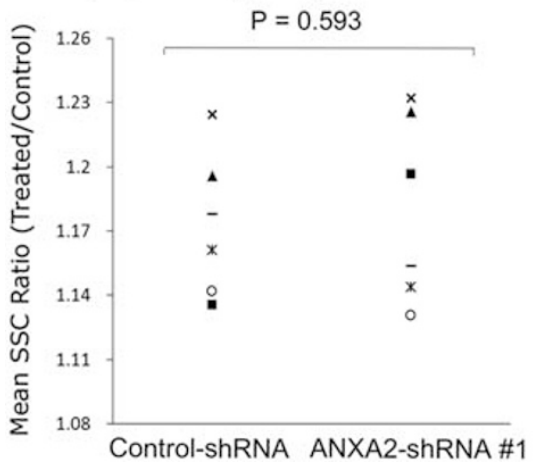

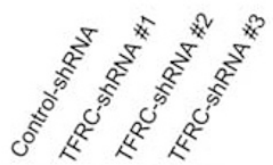

(C) TFRC - - - $98 \mathrm{kDa}$

(D) $\beta$-actin $-\longrightarrow 2 \mathrm{kDa}$

(C)/(D) $\quad 0.961 .300 .310 .65$

$\begin{array}{lllll}\text { Relative Ratio } & 1 & 1.35 & 0.32 & 0.67\end{array}$ of $(C) /(D)$

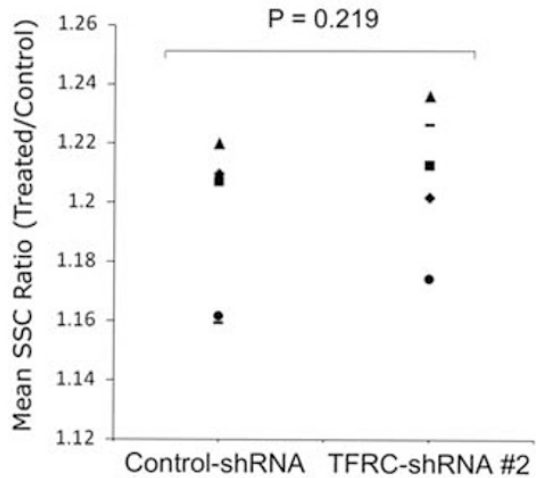

d
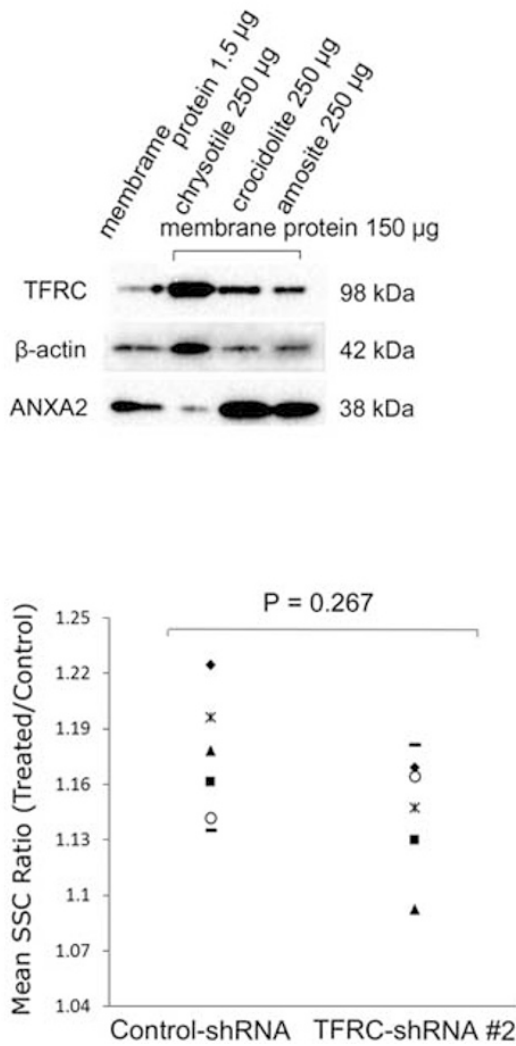
We then evaluated the differences in the protein adsorption properties of the three different types of asbestos using SDS-PAGE on the assumption that pristine asbestos could bind to cell-surface proteins by their protein adsorption properties. The proportions of the adsorbed proteins, as detected by silver staining, were nearly the same for crocidolite and amosite, but the proportion of each adsorbed protein between the two amphibole asbestos and chrysolite, which is a serpentine asbestos, was slightly different. This difference may partly be explained by crocidolite and amosite fibers being negatively charged at $\mathrm{pH}$ 7.4, whereas chrysotile fibers are positively charged under the same condition. Conversely, a previous report showed that the molecular weight and nature of the overall charge of the fibers and proteins are of little importance, but the specific area of the fiber and protein charge density have a role in adsorption. ${ }^{28}$

The process of cellular ingestion by which the plasma membrane folds inward to bring substances into the cell is called endocytosis. Phagocytosis is one of the important forms of endocytosis and is defined as the cellular engulfment of particles larger than $0.5 \mu \mathrm{m}$ in diameter. ${ }^{36}$ The lengths of asbestos fibers are usually longer than $0.5 \mu \mathrm{m}$, and bundles of asbestos fibers that are internalized in cells are sometimes wider than $0.5 \mu \mathrm{m}$. In addition, we observed that crocidolite fibers with a width $<0.1-0.2 \mu \mathrm{m}$ were engulfed by mesothelial cells in a morphologically similar manner to that of fiber bundles wider than $0.5 \mu \mathrm{m} .{ }^{30}$ Therefore, the endocytosis of asbestos fibers is suggested to be within a category of phagocytosis. Distinct from professional phagocytosis by monocytic/macrophage lineages and neutrophils, phagocytosis without triggering the immune response is called non-professional phagocytosis. ${ }^{36}$ Phagocytosis involves the recognition and binding of prey to receptors on the cell surface, and receptor-triggered actin remodeling is required. ${ }^{36,37}$ Although most of the receptors mediating phagocytosis are transmembrane proteins, some receptors might act only in binding particles and using accessory receptors to deliver the phagocytic signal. ${ }^{38}$ In addition, phagocytic receptors are generally activated when forming multimers; even before their lateral clustering occurs, several receptors must attach to the particle to secure it onto the phagocytic surface, a phenomenon that is against the tendency of the particle to detach by Brownian motion. ${ }^{37}$ Accordingly, we chose transmembrane proteins of the plasma membrane and proteins that were present at the cell surface as candidates for receptor proteins involved in asbestos phagocytosis.

Next, we showed the possibility that ANXA2 functions as a receptor for the endocytosis of crocidolite, through knockdown assays at first. Thereafter, we found that the antiANXA2 antibody (ab41803) reduced the crocidolite uptake by blocking the crocidolite adsorption to the cell surface

Table 5 Influence of ANXA2 knockdown on the crocidolite fiber uptake examined by two methods

\begin{tabular}{lcc}
\hline & Control-shRNA & ANXA2-shRNA no. 1 \\
\hline Mean SSC ratio (treated/control) & 1.16 & 3.104 \\
Cells without crocidolite $(\%)^{\mathrm{a}}$ & 33.12 & 48.8 \\
Cells including $<5$ bundles of crocidolite fiber (\%) & 54.7 & 43.03 \\
Cells including 5 or more bundles of crocidolite fiber/crocidolite in clumps (\%) & \\
Total counted cell numbers $^{\mathrm{a}}$ & 4.18 & 4.2
\end{tabular}

MeT5A cells were grown to $70 \%$ confluence $\left(2 \times 10^{4}\right.$ cells per $\mathrm{cm}^{2}, 24 \mathrm{~h}$ before $)$ and incubated with $2 \mu \mathrm{g} / \mathrm{cm}^{2}$ crocidolite for $2 \mathrm{~h}$. ${ }^{\text {a }}$ Counted by cell block.

Figure 4 Influence of shRNA (short hairpin RNA)-mediated knockdown of ANXA2 (annexin A2) and TFRC (transferrin receptor protein 1) on crocidolite and chrysotile uptake and blocking by anti-ANXA2 antibody on crocidolite uptake. (a) MeT5A cells were infected with retroviral particles harboring control-shRNA, three different ANXA2-specific shRNAs, or three different TFRC-specific shRNAs. The protein levels of ANXA2 and TFRC were estimated using western blotting, and the intensities of the bands were quantified. The expression of the proteins were normalized to the $\beta$-actin control and expressed with reference to the control-shRNA-transfected cells. (b) Crocidolite fibers $\left(2 \mu \mathrm{g} / \mathrm{cm}^{2}\right)$ were incubated with MeT5A cells for $2 \mathrm{~h}$. The mean side scatter (SSC) ratio (treated/control) was significantly reduced in ANXA2-shRNA no. 1-transfected cells, and not significantly different in TFRC-shRNA no. 2-transfected cells. (c) Crocidolite fibers $\left(2 \mu \mathrm{g} / \mathrm{cm}^{2}\right)$ were incubated with MeT5A cells for $2 \mathrm{~h}$. The mean SSC ratio (treated/control) was slightly but significantly reduced in anti-ANXA2 antibody (ab41803)-coated MeT5A cells. (d) Analysis of membrane proteins adsorbed by three different asbestos fibers. Crocidolite, chrysotile, and amosite fibers $(250 \mu \mathrm{g} / \mathrm{ml})$ were incubated with $150 \mu \mathrm{g} / \mathrm{ml}$ of MeT5A membrane fraction proteins, and the adsorbed proteins were analyzed by sodium dodecyl sulfate-polyacrylamide gel analysis (SDS-PAGE) with $1.5 \mu \mathrm{g}$ of membrane fraction proteins. Chrysotile adsorbed TFRC and $\beta$-actin more strongly than crocidolite and amosite, which adsorbed ANXA2 more strongly than chrysotile. (e) Chrysotile fibers $\left(5 \mu \mathrm{g} / \mathrm{cm}^{2}\right)$ were incubated with MeT5A cells for $2 \mathrm{~h}$. The mean SSC ratio (treated/control) was not significantly different in both ANXA2-shRNA no. 1-transfected cells and TFRC-shRNA no. 2-transferred cells. 

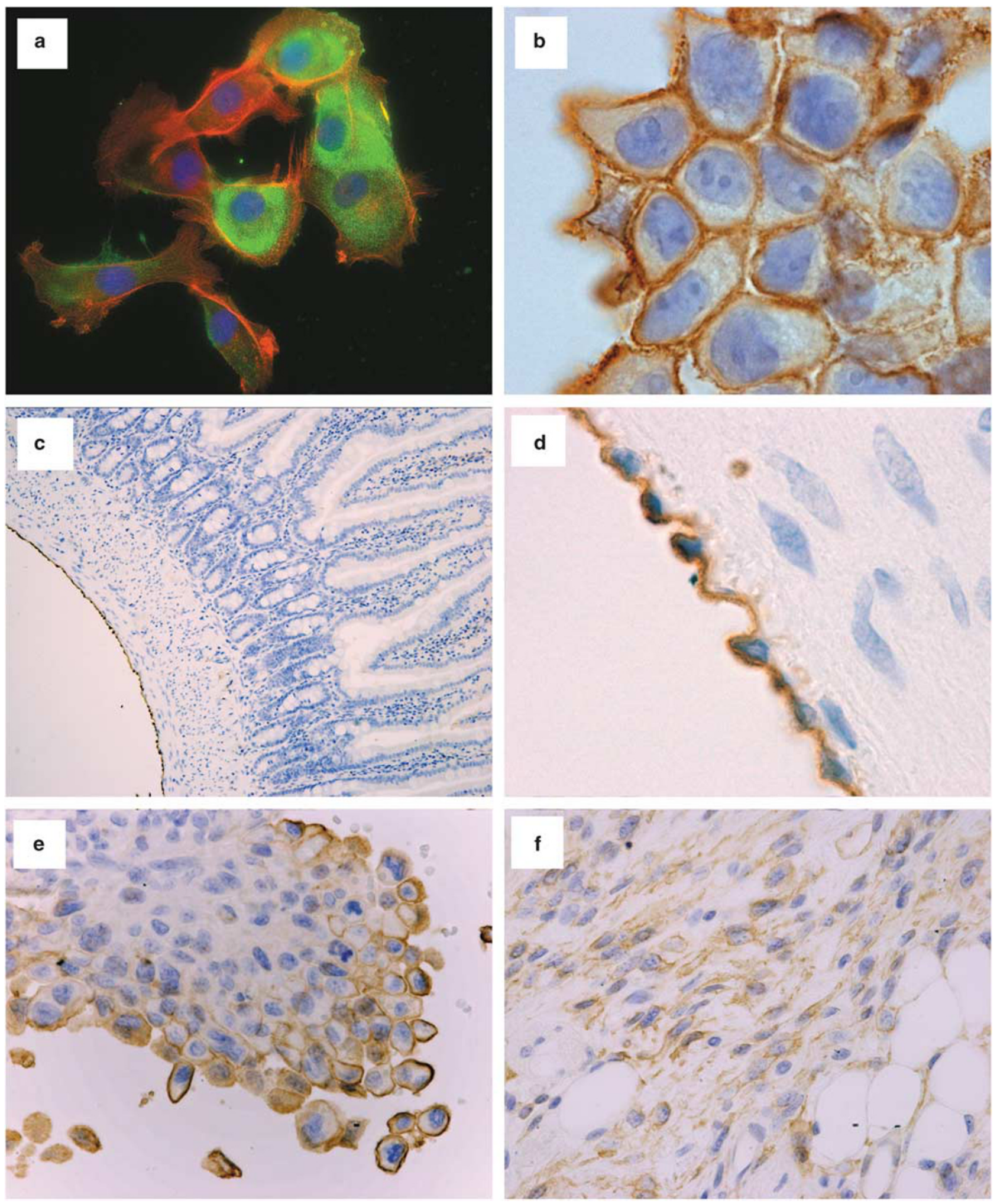

Figure 5 Immunohistochemical evaluation of annexin A2 (ANXA2) in mesothelial cells and tissues. (a) Immunofluorescence staining of ANXA2 (green), Hoechst (blue), and phallotoxin (red) in cultured MeT5A cells. (b-f) Immunohistochemical staining of ANXA2. ANXA2 expression was observed to cover the cells on a culture dish (a) and was found to be localized on the plasma membrane in the cell-block section of MeT5A cells (b). ANXA2 was expressed on the surface of the peritoneal mesothelium of rat (c and $\mathbf{d}$ ) and the plasma membrane of rat malignant mesothelioma cells, particularly on the peritoneal surface of the epithelioid type (e), whereas weaker expression was observed around sarcomatoid mesothelioma cells (f). 
ANXA2, whereas anti-ANXA2 antibody (sc-9061) did not reduce it. ANXA2 is a member of the annexin family of calcium-dependent, anionic phospholipid-binding proteins and exists as a monomer or as a heterotetrameric complex with S100A10, particularly on the cell surface. ${ }^{39}$ ANXA2 is composed of 339 amio acids, and the immunogens of antiANXA2 antibody (ab41803) are synthetic peptides derived from within residues 150-250 of human ANXA2, whereas the immunogens of anti-ANXA2 antibody (sc-9061) are amino acids 1-50 mapping epitope corresponding to amino acids 1-50 of human ANXA2. In ANXA2, although the first 14 residues of the $\mathrm{N}$-terminal domain harbors a binding site for S100A10, ${ }^{40}$, our study suggested that the $\mathrm{N}$-terminal domain was not so important for crocidolite adsorption. In fact, the interaction sites of cell-surface ANXA2 with crocidolite could be multiple and distributed widely. We also showed that ANXA2 is highly expressed in the plasma membrane of mesothelial and mesothelioma cells, particularly at the apical side. This is consistent with the receptor role of ANXA2 because mesothelial cells face asbestos fibers at the apical side in vivo, and thus the receptor proteins that are involved in asbestos phagocytosis should also be at the apical membrane side.

S100A10-dependent plasmin generation functions to stimulate the breakdown of fibrin blood clots (fibrinolysis). ${ }^{41}$ Extracellularly, ANXA2 also interacts with receptors, such as Toll-like receptor 4, through which it can deliver inflammatory signals to macrophages and modulate macrophage function. ${ }^{42}$ ANXA2 has been reported to have some roles in endocytosis, such as endosome biogenesis and early-to-late endosome transport. ${ }^{43}$ Cell-surface ANXA2 is required for the binding and internalization of progastrin in intestinal cells, potentially by clathrin-mediated endocytosis. ${ }^{44}$ Intracellularly, ANXA2 is present on the plasma membrane and early endosome and interacts with actin to act as a regulator of membra-cytoskeleton dynamics. ${ }^{45-47}$ It was reported that ANXA2 is involved in the phagocytosis of the shed photoreceptor outer segment by pigment epithelial cells in the retina. ${ }^{47}$ Furthermore, ANXA2 is known to be present in various cells such as endothelial cells, monocytes, macrophages, and most cancer cells. ${ }^{39,48,49}$

Asbestos is neither an intracellular pathogen that has developed specific ligand proteins to enter nonprofessional phagocytes nor an apoptotic body that arises during the normal physiological state and has a phagocytic removal system through nonprofessional phagocytes. In addition, no counterpart to asbestos exists in vivo; therefore, it is unlikely that mesothelial cells have specific receptors that mediate asbestos phagocytosis without an opsonin effect, such as coating by vitronectin. ${ }^{24}$ Therefore, we assume that the protein adsorption property of asbestos, with which it can bind to various proteins on the cell surface and remain there for a while, may account for the reason why asbestos can be actively engulfed by nonprofessional phagocytes. Supporting this idea, the nonprofessional phagocytic system of asbestos is not specific to mesothelial cells. ${ }^{13,25}$
The transferrin receptor protein is an integral membrane protein that mediates the uptake of transferrin-iron complexes, and TFRC is considered the major protein responsible for iron uptake. ${ }^{50}$ TFRC is known to be involved in clathrinmediated endocytosis, which is a form of endocytosis different from phagocytosis. In our study, the knockdown of TFRC did not decrease crocidolite uptake by MeT5A cells. Therefore, TFRC was suggested not to have a significant role in crocidolite phagocytosis. Interestingly, unlike crocidolite, knockdown of TFRC tended to decrease the amount of phagocytic uptake of chrysotile by MeT5A cells, although knockdown of ANXA2 did not decrease it at all. This is consistent with our finding that chrysotile presented with high adsorbability to TFRC and low adsorbability to ANXA2 compared with crocidolite (Figure 4d), supporting the idea that the protein adsorption property of asbestos has an important role in phagocytosis by mesothelial cells. Recently, the biomolecular corona, which results from adsorption activity, has called attention in terms of the biological activity of nanomaterials. ${ }^{51}$ Further studies are warranted to understand the molecular defense mechanisms against nanosized fibrous materials.

In conclusion, we demonstrated that significant amounts of both crocidolite and chrysotile fibers enter the cells without serum, and serum was not essential for asbestos endocytosis. Next, we distinguished membrane proteins exposed to the extracellular environment that were adsorbed to asbestos as candidate proteins for the receptor of asbestos phagocytosis, using extensive protein identification with mass spectrometry. Considering the decrease in crocidolite uptake by ANXA2 knockdown, direct blockade using antiANXA2 antibody and its distribution on the apical membrane side of mesothelial cells, we suggest that ANXA2 is well involved in crocidolite phagocytosis and could be its putative receptor.

Supplementary Information accompanies the paper on the Laboratory Investigation website (http://www.laboratoryinvestigation.org)

\section{ACKNOWLEDGMENTS}

We acknowledge the Division for Medical Research Engineering, Nagoya University Graduate School of Medicine, for technical support of mass spectrometry, and we also thank Nobuaki Misawa for excellent technical assistance regarding the pathologic specimens. This work was supported in part by the National Cancer Center Research and Development Fund (25-A-5), a grant-in-aid for research from the Ministry of Education, Culture, Sports, Science, and Technology (MEXT) of Japan (24390094; 221S0001-04; 24108001) and a grant-in-aid from the Japan Society for the Promotion of Science Fellows (to HN)

\section{DISCLOSURE/CONFLICT OF INTEREST}

The authors declare no conflict of interest.

1. Vitra RL. Some facts about asbestos. USGS Fact Sheet FS-012-01 2001

2. IARC Asbestos (Chrysotile, Amosite, Crocidolite, Tremolite, Actinolite, and Anthophyllite); IARC Monographs on the Evaluation of Carcinogenic Risks to Humans, Vol. 100C, Lyon, France, 2012, pp 219-309. 
3. Aierken D, Okazaki Y, Chew SH, et al. Rat model demostrates a high risk of tremolite but a low risk of anthophyllite for mesothelial carcinogenesis. Nagoya J Med Sci 2014;76:149-160.

4. Hodgson J, Darnton A. The quantitative risks of mesothelioma and lung cancer in relation to asbestos exposure. Ann Occup Hyg 2000;44:565-601.

5. Roggli VL, Oury TD, Sporn TA eds). Pathology of Asbestos-Associated Diseases. 2nd edn. Springer: New York, NY, USA, 2004.

6. O'Reilly KM, McLaughlin AM, Beckett WS, et al. Asbestos-related lung disease. Am Fam Phys 2007;75:683-688.

7. Carbone M, Emri S, Dogan AU, et al. A mesothelioma epidemic in Cappadocia: scientific developments and unexpected social outcomes. Nat Rev Cancer 2007;7:147-154.

8. Cavazza A, Travis LB, Travis WD, et al. Post-irradiation malignant mesothelioma. Cancer 1996;77:1379-1385.

9. Yang H1, Testa JR, Carbone M. Mesothelioma epidemiology, carcinogenesis, and pathogenesis. Curr Treat Options Oncol 2008;9:147-157.

10. Toyokuni S. Mechanisms of asbestos-induced carcinogenesis. Nagoya J Med Sci 2009;71:1-10.

11. McDonald A, McDonald J, Pooley F. Mineral fibre content of lung in mesothelial tumours in North America. Ann Occup Hyg 1982;26: 417-422.

12. Kamp DW, Graceffa P, Pryor WA, et al. The role of free radicals in asbestos-induced diseases. Free Radic Biol Med 1992;12:293-315.

13. Jiang $\mathrm{L}$, Nagai $\mathrm{H}$, Ohara $\mathrm{H}$, et al. Characteristics and modifying factors of asbestos-induced oxidative DNA damage. Cancer Sci 2008;99: 2142-2151.

14. Wang $N$, Jaurand $M$, Magne $L$, et al. The interactions between asbestos fibers and metaphase chromosomes of rat pleural mesothelial cells in culture. A scanning and transmission electron microscopic study. Am J Pathol 1987;126:343-349.

15. Nagai $H$, Ishihara $T$, Lee $W H$, et al. Asbestos surface provides a niche for oxidative modification. Cancer Sci 2011;102:2118-2125.

16. Liu W, Ernst JD, Broaddus VC. Phagocytosis of crocidolite asbestos induces oxidative stress, DNA damage, and apoptosis in mesothelial cells. Am J Resp Cell Mol Biol 2000;23:371-378.

17. Hillegass JM, Shukla A, Lathrop SA, et al. Inflammation precedes the development of human malignantmesotheliomas ina SCID mousexenograft model. Ann N Y Acad Sci 2010;1203:7-14.

18. Carbone M, Ly BH, Dodson RF, et al. Malignant mesothelioma: facts, myths and hypotheses. J Cell Physiol 2011;227:44-58.

19. Goodglick LA, Kane AB. Role of reactive oxygen metabolites in crocidolite asbestos toxicity to mouse macrophages. Cancer Res 1986:46:5558-5566.

20. Carbone $\mathrm{M}$, Yang $\mathrm{H}$. Molecular pathways: targeting mechanisms of asbestos and erionite carcinogenesis in mesothelioma. Clin Cancer Res 2012;18:598-604

21. Jaurand MC, Kaplan H, Thiollet J, et al. Phagocytosis of chrysotile fibers by pleural mesothelial cells in culture. Am J Pathol 1979;94:529-538.

22. McLemore T, Corson M, Mace M, et al. Phagocytosis of asbestos fibers by human pulmonary alveolar macrophages. Cancer Lett 1979;6: 183-192.

23. Nagai $\mathrm{H}$, Okazaki $\mathrm{Y}, \mathrm{Chew} \mathrm{S}$, et al. Diameter of multi-walled carbon nanotubes is a critical factor in mesothelial injury and subsequent carcinogenesis. Proc Natl Acad Sci USA 2011;108:E1330-E1338.

24. Boylan AM, Sanan DA, Sheppard D, et al. Vitronectin enhances internalization of crocidolite asbestos by rabbit pleural mesothelial cells via the integrin $\alpha \mathrm{v} \beta 5$. J Clin Invest 1995;96:1987-2001.

25. Pande $\mathrm{P}$, Mosleh TA, Aust AE. Role of $\alpha \mathrm{v} \beta 5$ integrin receptor in endocytosis of crocidolite and its effect on intracellular glutathione levels in human lung epithelial (A549) cells. Toxicol Appl Pharmacol 2006;210:70-77.

26. Wu J, Liu W, Koenig K, et al. Vitronectin adsorption to chrysotile asbestos increases fiber phagocytosis and toxicity for mesothelial cells. Am J Physiol Lung Cell Mol Physiol 2000;279:L916-L923.
27. Valerio $F$, Balducci D, Scarabelli L. Selective adsorption of serum proteins by chrysotile and crocidolite. Environ Res 1986;41:432-439.

28. Valerio F, Balducci D, Lazzarotto A. Adsorption of proteins by chrysotile and crocidolite: role of molecular weight and charge density. Environ Res 1987;44:312-320.

29. Kubo $\mathrm{Y}$, Takenaka $\mathrm{H}, \mathrm{Nagai} \mathrm{H}$, et al. Distinct affinity of nuclear proteins to the surface of chrysotile and crocidolite. J Clin Biochem Nutr 2012;51:221-226.

30. Yamashita $\mathrm{K}$, Nagai $\mathrm{H}$, Kondo $\mathrm{Y}$, et al. Evaluation of two distinct methods to quantify the uptake of crocidolite fibers by mesothelial cells. J Clin Biochem Nutr 2013;53:27-35.

31. MacCorkle RA, Slattery SD, Nash DR, et al. Intracellular protein binding to asbestos induces aneuploidy in human lung fibroblasts. Cell Motil Cytoskeleton 2006;63:646-657.

32. Toyokuni S, Kawaguchi W, Akatsuka S, et al. Intermittent microwave irradiation facilitates antigen-antibody reaction in Western blot analysis. Pathol Int 2003;53:259-261.

33. Kamp DW, Dunne M, Anderson JA, et al. Serum promotes asbestosinduced injury to human pulmonary epithelial cells. J Lab Clin Med 1990;116:289-297.

34. Resnick D, Freedman NJ, Xu S, et al. Secreted extracellular domains of macrophage scavenger receptors form elongated trimers which specifically bind crocidolite asbestos. J Biol Chem 1993;268: 3538-3545.

35. Walkey CD, Olsen JB, Guo H, et al. Nanoparticle size and surface chemistry determine serum protein adsorption and macrophage uptake. J Am Chem Scoc 2012;134:2139-2147.

36. Melendez AJ, Tay HK. Phagocytosis: a repertoire of receptors and $\mathrm{Ca}(2+)$ as a key second messenger. Bioscience Rep 2008;28:287-298.

37. Flannagan RS, Jaumouille V, Grinstein S. The cell biology of phagocytosis. Annu Rev Pathol-Mech 2012;7:61-98.

38. Savill J.. Apoptosis. Phagocytic docking without shocking. Nature 1998;392:442-443.

39. Bharadwaj A, Bydoun M, Holloway R, et al. Annexin A2 heterotetramer: structure and function. Int J Mol Sci 2013;14:6259-6305.

40. Gerke V, Moss SE. Annexins: from structure to function. Physiol Rev 2002;82:331-371.

41. Hou $Y$, Yang $L$, Mou $M$, et al. Annexin A2 regulates the levels of plasmin S100A10 and Fascin in L5178Y cells. Cancer Invest 2008;26:809-815.

42. Swisher JF, Burton N, Bacot SM, et al. Annexin A2 tetramer activates human and murine macrophages through TLR4. Blood 2010;115: 549-558.

43. Morel E, Parton RG, Gruenberg J. Annexin A2-dependent polymerization of actin mediates endosome biogenesis. Dev Cell 2009;16: 445-457

44. Sarkar S, Kantara C, Singh P. Clathrin mediates endocytosis of progastrin and activates MAPKs: role of cell surface annexin A2. Am J Physiol-Gastr L 2012;302:G712-G722.

45. Emans N, Gorvel JP, Walter C, et al. Annexin II is a major component of fusogenic endosomal vesicles. J Biol Chem 1993;120:1357-1369.

46. Hayes MJ, Rescher U, Gerke V, et al. Annexin-actin interactions. Traffic 2004;5:571-576.

47. Law $A L$, Ling $Q$, Hajjar $K A$, et al. Annexin $A 2$ regulates phagocytosis of photoreceptor outer segments in the mouse retina. Mol Biol Cell 2009;20:3896-3904.

48. Tanaka T, Kondo S, Iwasa $Y$, et al. Expression of stress-response and cell proliferation genes in renal cell carcinoma induced by oxidative stress. Am J Pathol 2000;156:2149-2157.

49. Tanaka T, Akatsuka S, Ozeki $M$, et al. Redox regulation of annexin 2 and its implications for oxidative stess-induced renal carcinogenesis and metastasis. Oncogene 2004;23:3980-3989.

50. Aisen P. Transferrin receptor 1. Int J Biochem Cell Biol 2004;36:2137-2143.

51. Monopoli MP, Aberg C, Salvati A, et al. Biomolecular coronas provide the biological identity of nanosized materials. Nat Nanotechnol 2012;7:779-786. 